\title{
Prevalence of Strabismus and its type in Pediatric age group 6- 15 years in a tertiary eye care hospital, Karachi
}

\begin{abstract}
Objective: To know the prevalence and types of strabismus in patients presenting at tertiary eye care hospital, Karachi.

Material and Method: This hospital based cross sectional study was carried out at pediatric clinic of Al-Ibrahim Eye Hospital during June to August, 2017. Nonprobability purposive sampling was used. All patients diagnosed with strabismus under 6 to 15 years of age either male or female and having no previous history of surgery and also signed the consent form were included. Any Surgery and other eye complications were excluded from study. All ocular examination belongs to strabismus were performed. SPSS version 20.0 was used to analyze the data.

Results: Prevalence of strabismus was found to be $6.2 \%$ according to total numbers of patient whereas according to 74 patients (Numbers of Patients found during study), $5.2 \%$ of strabismus was found. Most common. 40 (46.0\%) age group was 6-9 years. The vast majority of cases were of manifest strabismus and the highest frequency found alternate esotropia $14(16.1 \%)$. The strabismus includes esotropic $40(45.97 \%)$, exotropic $25(28.73 \%)$, third nerve palsies $3(3.44 \%)$, Duane retraction syndrome 1 $(1.14 \%)$, nystagmus $3(3.44 \%)$, amblyopia $3(3.44 \%)$, esophoria $2(2.29 \%)$, exophoria $3(3.44 \%)$ and psuedostrabismus 7 (8.045\%). Conclusion: Prevalence of strabismus was found to be high. The manifest strabismus was more common than latent strabismus. Squint has immediate (Childhood) and long-term (I.e. during adulthood) effects on the life of the children. Timely diagnosis and treatment can improve prognosis and thus quality of life. On the basis of diagnosis alternate exotropia and alternate esotropia was observed in maximum respondence.
\end{abstract}

Keywords: strabismus, squint, crossed eye, heterotropia, heterophoria, neurological disorder
Volume 8 Issue I - 2019

\author{
Paras Azam,' Neelam Nausheen,' \\ Muhammad Faisal Fahim² \\ 'Optometrist, Department of Ophthalmology,Akhter Eye \\ Hospital, Pakistan \\ ${ }^{2}$ Researcher, Department of BUCPT, Bahria University Medical \\ \& Dental College, Pakistan
}

Correspondence: Muhammad Faisal Fahim, M.Sc. (Statistics), Researcher, Department of BUCPT Bahria University Medical \& Dental College, Karachi-Pakistan, Email faisalfahim88@hotmail.com

Received: February 05, 2019 | Published: February 14, 2019

\section{Introduction}

Strabismus, also called squint, tropia and heterotropia, is a common ocular disorder having $1 \%$ to $4 \%$ of prevalence. ${ }^{1}$ There are two types of strabismus: concomitant and incomitant. Concomitant strabismus is a condition in which the ocular angle of deviation remains constant in each direction of gaze. It includes the most common types of strabismus, including exotropia, esotropia, hypetropia, monofixation syndrome and microstrabismus. In the incomitant strabismus, which is also called as complex or paralytic strabismus, the misalignment of eyes or the angle of deviation differs with each direction of gaze. According to different surveys the global prevalence of strabismus shows the estimated prevalence of squint in the general population is from 2 to $5 \%$. Between 5 and 15 million individuals in the United States may have this condition, several studies of clinical populations have reported that esotropia appears to occur approximately 3 times as often as exotropia in children. ${ }^{2}$ However, the National Health Survey of individual's 4-74 years of age found a higher prevalence of exotropia $(2.1 \%)$ than esotropia $(1.2 \%)$ in the U.S population. This difference is probably related to the fact that the overall prevalence of strabismus in persons 55-75 years of age (in whom exotropia is more common) is $6.1 \%$ substantially greater than for very young children $1-3$ years of age $(1.9 \%)$ or children and adults $4-54$ years of age $(3.3 \%) .{ }^{3}$ The prevalence of exotropia may be underestimated, because it is most often an intermittent strabismus. For Hispanic/Latino and African American children ages 6-72 months in Los Angeles, California. The prevalence of strabismus was $2.4 \%$ for the former and $2.5 \%$ for the latter group. Exotropia was more common than esotropia. ${ }^{4}$ Approximately $50 \%$ of all childhood esotropia are either fully or partially accommodative. An esotropia is partially accommodative when the accommodative factors of uncorrected hyperopia and/or a high accommodative convergence/accommodation (AC/A) ratio contribute to, but do not account for. The entire strabismus, non-accommodative esotropia is the second most common form of childhood esotropia, accounting for approximately $10 \%$ of all strabismus. Infantile esotropia accounts for approximately $8.1 \%$ of cases of esotropia, affecting 1 in every 100-500 persons. ${ }^{5}$ Intermittent exotropia is the most common type of exotropia, affecting nearly $1 \%$ of the population. Exotropia has been reported to be more prevalent among Asian and African American populations than among Caucasians women comprise $60-70 \%$ of patients with exotropia. ${ }^{6}$ The prevalence of strabismus in Nigeria was $0.14 \%$. $^{7}$ In Pakistan, children under the age of 15 years account for $45 \%$ of the total population. The overall estimated prevalence of strabismus in Pakistan is 5.4\%. Out of this $2.5 \%$ strabismus patients are under the age of the 5 years while $2.9 \%$ patients are over the age of 5 years. The national prevalence of squint $5.4 \%$ suggests that there are 7.02 million patients with strabismus in a population of 130 million. ${ }^{8}$ The prevalence of strabismus conducted in Lady Reading Hospital, Peshawar, and The frequency of comitant convergent squint found in this study is $2.5 \%$ is almost similar to the Prevalence of squint in Pakistan which is $2.75 \% .^{9}$ In the population of Rawalpindi, the frequency of all vertical deviations was $11.4 \%$. Pure vertical deviation 
was seen in about $2 \%$ of all strabismus cases and $60 \%$ of the patients with vertical deviation were under 10 years of age, with one third under 5 years. ${ }^{8}$ The prevalence of strabismus and amblyopia varies in different parts of the world. While studies in African children showed a prevalence of between $0.5 \%$ and $4.4 \%$, its prevalence in other parts of the world varies between $0.9 \%$ and $7.4 \% .^{10}$ This study was design to know the frequency and types of strabismus in patients presenting at tertiary eye care hospital, Karachi.

\section{Methodology}

This was a hospital-based cross-sectional study with nonprobability, purposive sampling carried out at Pediatric ophthalmology department of Al-Ibrahim Eye Hospital (AIEH) Karachi. The duration is from June to Nov 2017. Ethical approval was taken from the institutional review board of the institution. Sample size was calculated from the online software Raosoft.com by taking 95\% Confidence Interval, 5\% Margin of error, Probability of 50\%, Expected population of 300 . The required sample size $=169$ (drawn from software) Inclusion criteria was age 6 to 15 years with no history of previous squint surgery. Both genders were included. Patients under the age of six years, already squint surgery done previously and those patients who did not give consent were excluded. The standard protocol for examination for all patients who were evaluated at the general outpatient clinic: The demographic data, history of prematurity, family history of squint, age of onset ,type of squint, were retrieved from the case notes, Visual acuity of every patient were check and recorded separately both for near and distance, with and without glasses, and with pin-hole. The anterior segment will examine with a slit-lamp. Orthoptic assessment included cover uncover test, Hirschberg, ocular motility, prism cover test, krimsky, prism reflex tests at $33 \mathrm{~cm}$ for near, and at 6 meter for distance with spectacles and without spectacles. Cycloplegic refraction of all patients will do using cyclopentolate $0.5 \%-1 \%$ eye. All the patients were examined after obtaining a fully informed consent. Instrument used were Illuminated Snellen Chart visual acuity chart, Prism bar (for PCT), Targets (for performing near PCT), Torch, Ophthalmoscope, Profroma.

Data analysis was done on Statistical package of social sciences (SPSS) version 20.0. All continuous variables were presented as Mean \pm Standard Deviation. The entire categorical variables are shown as frequency and percentages. Statistical charts are present in the form of Bar chart, Frequency curve \& Pie chart etc.

\section{Result}

A total of 87 patients fulfilled the inclusion criteria for the study. Among them, 46 were female, and 41 were male. The mean age at presentation was 9.99 , in which maximum age was in between 6-9 years $40(46.0 \%)$, Initially the more patients had visual acuity was $>6 / 12,48(55.2 \%)$ in right eye while in left was $>6 / 12,57(65.5 \%)$, whether in near was $>=\mathrm{N} 10,63(72.4 \%)$ in right eye where in left eye was also $>=$ N10, $65(74.7 \%)$. Out of 87 patients $74(85.1 \%)$ patients were found with strabismus rest of patients found with pseudo strabismus (absence with strabismus) 13 (14.9\%). The most affected eye was asset as left eye $37(42.5 \%)$.when the distance and near Hirschberg taken the most frequency had seen in between $>15$ 30 degree, during investigation procedure the most seen deviation in cover test was manifest deviation $69(79.3 \%)$, latent were 5(5.7\%) and remaining patients were found with no deviation in the eye during cover test performance $13(14.9 \%)$, as the visual acuity had found good in most of patients the technique of measurement of deviation performed according to patients visual acuity therefore, PCT had shown the highest frequency $67(77.0 \%)$ during data collection procedure. Measurement of deviation results shows distance> 30 60prsim diopters in right and left eye $22(25.3 \%)$ and $21(24.1 \%)$, similarly in near the greatest measurement was in between $>30-60$ prism diopters in right eye and left eye 18 (20.7\%) and 22 (25.3\%), the diagnosis of all the strabismus patients showed the frequency of concomitant was $76(87.4 \%)$ and incomitant was $4(4.6 \%)$ where in concomitant the most frequent diagnosis acquisition was alternate esotropia 14 (16.1\%)and alternate exotropia $13(14.9 \%)$ and the least common was esotropia with DVD with amblyopia 1(1.1\%), convergence excess esotropia $1(1.1 \%)$, where in incomitancy there was only few case presented during study duration and that is Duane retraction syndrome $1(1.1 \%)$ and III nerve palsy $3(3.4 \%)$.

In 6-9 age group the highest cases were found with alternate esotropia 6 while intermittent distance exotropia was 5 cases, alternate exotropia and constant esotropia was 4 cases and no case were found of hypertropia and hypotropia (Figure 1-4), (Table 1-3).

\section{DMALE GFEMALE}

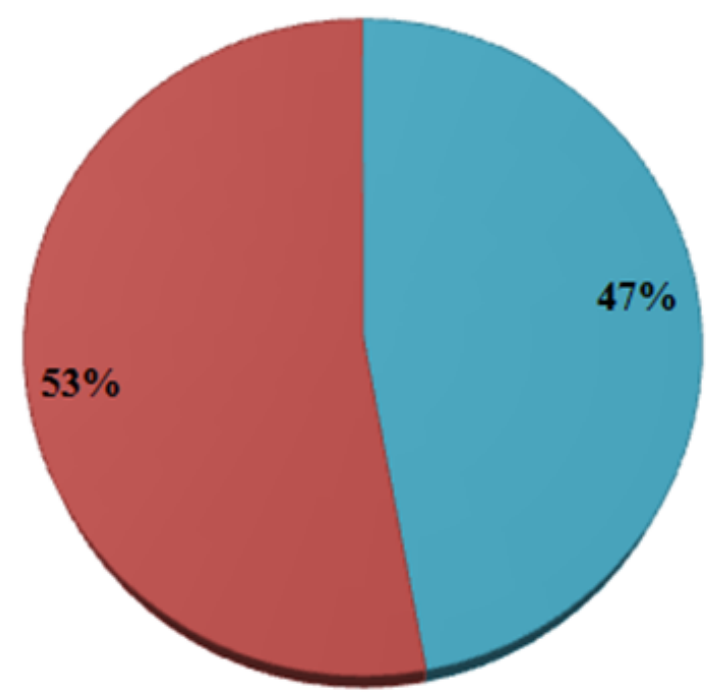

Figure I Frequency of gender.

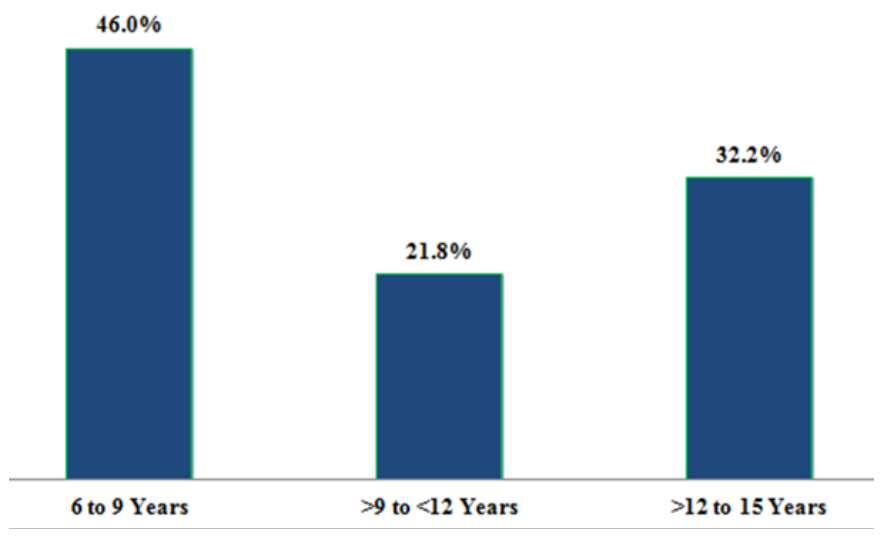

Figure 2 Frequency of age. 
Table I Indicates Cover Test, Its Results \& types of Strabismus

\begin{tabular}{lll}
$\begin{array}{l}\text { Frequency of cover test } \\
\text { Strabismus }\end{array}$ & Frequency & Percentage \\
\hline Manifest & 69 & 79.3 \\
Latent & 5 & 5.7 \\
Orthophoria & 13 & 14.9 \\
Total & 87 & 100 \\
\hline
\end{tabular}

Manifest results of cover test

\begin{tabular}{lll} 
Cover test & Frequency & Percentage \\
\hline Esotropia & 40 & 57.97 \\
Exotropia & 29 & 42.3 \\
Total & 69 & 100 \\
\hline
\end{tabular}

Latent results of cover test

\begin{tabular}{lll} 
Cover test & Frequency & Percentage \\
\hline Esophoria & 2 & 40 \\
Exophoria & 3 & 60 \\
Total & 5 & 100 \\
\hline
\end{tabular}

\section{Frequency of concomitant and inconcomitant strabismus}

\begin{tabular}{lll} 
Strabismus & Frequency & Percentage \\
\hline Concomitant & 76 & 95 \\
Inconcomitant & 4 & 5 \\
Total & 80 & 100
\end{tabular}

Table 2 Different types of Diagnosis in Strabismus in relation with Gender

\begin{tabular}{|c|c|c|c|}
\hline \multirow[t]{2}{*}{ Diagnosis } & \multicolumn{2}{|c|}{ Gender } & \multirow{2}{*}{ Tota } \\
\hline & Male & Female & \\
\hline Accommodative esotropia & 2 & 1 & 3 \\
\hline Constant esotropia & 4 & 4 & 8 \\
\hline Esotropia ē hypertropia & 4 & 1 & 5 \\
\hline Alternate esotropia & 6 & 8 & 14 \\
\hline Esotropia ē amblyopia & 6 & 2 & 8 \\
\hline Esotropia ē dvd ē amblyopia & 0 & 1 & 1 \\
\hline Convergence excess esotropia & 0 & 1 & 1 \\
\hline Constant exotropia & 1 & 1 & 2 \\
\hline Idxt & 1 & 5 & 6 \\
\hline Exotropia ē hypertropia & 0 & 2 & 22 \\
\hline Alternate exotropia & 9 & 4 & 13 \\
\hline Exotropia ē amblyopia & 1 & 1 & 2 \\
\hline III Nerve Palsy & 1 & 2 & 3 \\
\hline Duane's Syndrome & 0 & 1 & 1 \\
\hline Esophoria & 2 & 0 & 2 \\
\hline Exophoria & 0 & 3 & 3 \\
\hline Pseudostrabismus & 4 & 9 & 13 \\
\hline Total & 41 & 46 & 87 \\
\hline
\end{tabular}

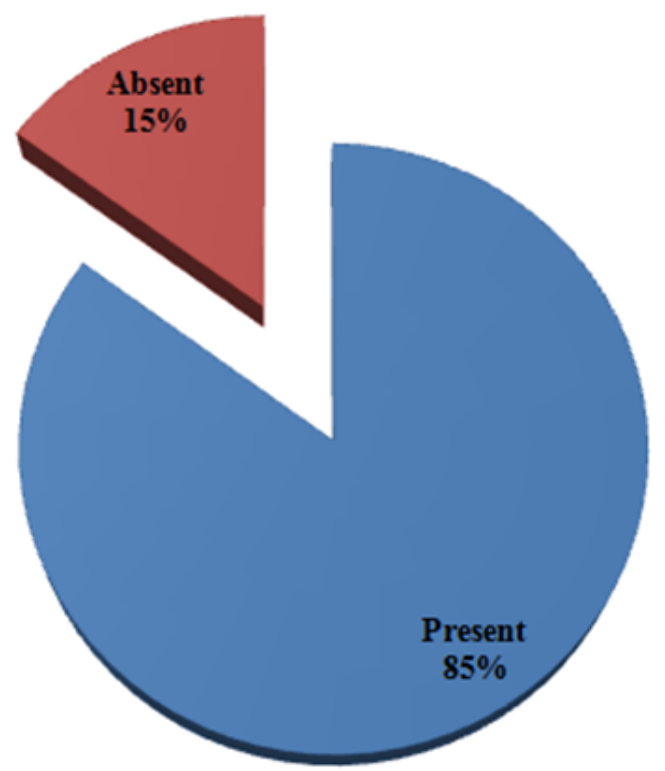

Figure 3 Strabismus.

Table 3 Different types of Diagnosis in Strabismus in relation with Age (years)

\begin{tabular}{|c|c|c|c|c|}
\hline \multirow[t]{2}{*}{ Diagnosis } & & \multicolumn{2}{|r|}{ Total } \\
\hline & $\begin{array}{l}6 \text { to } 9 \\
\text { year }\end{array}$ & $\begin{array}{l}>9 \text { to }<12 \\
\text { year }\end{array}$ & $>12$ & 15 year \\
\hline Accommodative esotropia & 3 & 0 & 0 & 3 \\
\hline Constant esotropia & 4 & 1 & 3 & 8 \\
\hline Esotropia ē Hypertropia & 1 & 2 & 2 & 5 \\
\hline Alternate esotropia & 6 & 3 & 5 & 14 \\
\hline Esotropia $\bar{e}$ amblyopia & 4 & 3 & 1 & 8 \\
\hline Esotropia ē DVD ē amblyopia & 0 & 0 & 1 & 1 \\
\hline Convergence excess esotropia & 1 & 0 & 0 & 1 \\
\hline Constant exotropia & 0 & 1 & 1 & 2 \\
\hline Idxt & 5 & 0 & 1 & 6 \\
\hline Exotropia ē hypertropia & 0 & 1 & 1 & 2 \\
\hline Alternate exotropia & 4 & 2 & 7 & 13 \\
\hline Exotropia ē amblyopia & 1 & 0 & 1 & 2 \\
\hline III Nerve Palsy & 0 & 1 & 2 & 3 \\
\hline Duane's syndrome & 1 & 0 & 0 & 1 \\
\hline Esophoria & 1 & 0 & 1 & 2 \\
\hline Exophoria & 1 & 1 & 1 & 3 \\
\hline Pseudostrabismus & 7 & 4 & 1 & 13 \\
\hline Total & 40 & 19 & 28 & 87 \\
\hline
\end{tabular}




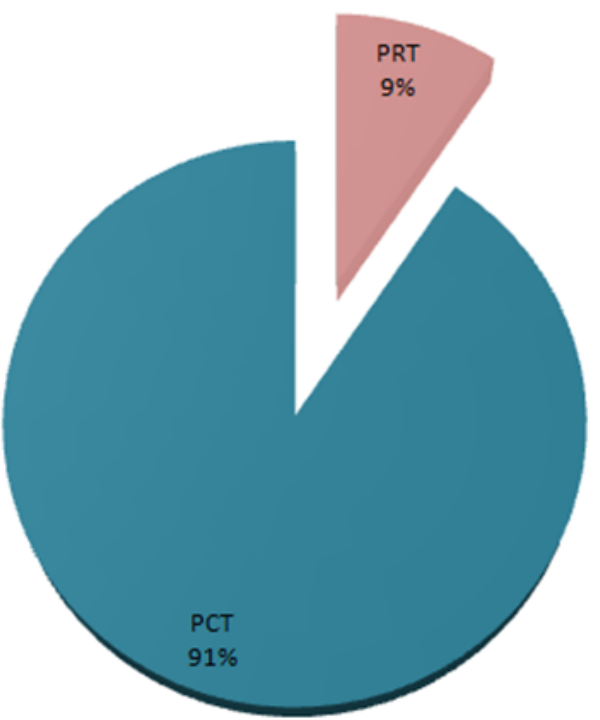

Figure 4 Method of measurement.

\section{Discussion}

Our study estimated the prevalence of strabismus in children 6-15 years in pediatric unit of tertiary eye care hospital. Prevalence of strabismus was found to be $6.2 \%$ according to total numbers of patient whereas according to 74 patients (Numbers of Patients found during study), $5.2 \%$ of strabismus was found. The frequency of concomitant strabismus was $76(87.4 \%)$ while incomitant showed least than concomitant that is $4(4.6 \%)$ the frequency of manifest strabismus was $69(79.3 \%)$ and latent was $5(5.7 \%)$ respectively, the most affected eye were found to be left $13(14.9 \%)$.In comparison with the study published in china showed prevalence of amblyopia in our populationbased sample of 36 to 72 month-old preschool children from Yuhua District of Nanjing was $1.20 \% .^{11}$ The prevalence of amblyopia in Iran was $0.19 \%-3.9 \% .^{12}$

The prevalence of amblyopia was found to be $1.1 \%$ in young Singaporean-Chinese children. 8 A total of 200 students of a school in Lahore, Pakistan, were examined for visual impairments and 3\% of them were found to be amblyopic. ${ }^{13}$ From different studies it can be observed that prevalence of amblyopia is around $1.09 \%$ to $3 \%$ of population of any area. In literature, the most common type of amblyopia is anisometropic.

Results from this study clearly depicted that the type of amblyopia was independent of gender. It can affect anyone regardless of gender during their early years of childhood. Moreover, anisometropic amblyopia was found to be the most common type of amblyopia in both genders. The findings of this study are similar to previous studies, ${ }^{14,15}$ and in contrast with the study in which the most common type is strabismic. The results are also opposed to a study which concluded that amblyopia is more common in males than females. ${ }^{16}$

In this study the prevalence of strabismus was found more common in 6 - 9 age group $40(46.0 \%)$ and $\geq 12$ to 15 years of age group, most frequent condition was alternate esotropia and alternate exotropia in these groups. The vast majority of cases were of manifest strabismus and the highest frequency found alternate esotropia 14 (16.1\%). The strabismus includes esotropic 40 (45.97\%), exotropic $25(28.73 \%)$, third nerve palsies 3 (3.44\%), Duane retraction syndrome 1 (1.14\%), nystagmus $3(3.44 \%)$, amblyopia $3(3.44 \%)$, esophoria $2(2.29 \%)$, exophoria 3(3.44\%) and psuedostrabismus 7 (8.045\%). Comparison with earlier studies that had been performed by Awan et al., ${ }^{13}$ at Lahore, Pakistan, revealed that meridional amblyopia is the most common type of amblyopia being $1.5 \%$ ametropic, while anisometropic and strabismic types of amblyopia were $0.5 \%$. In our study, anisometropia was $69.23 \%$, strabismic was $21.54 \%$, while meridional and sensory deprivation types of amblyopia were $9.23 \%$. This similarity co-relates with the study performed in Iran, which concluded that the prevalence of amblyopia was $2.1 \%$ and anisometropia was the most common cause $(54.2 \%)$ while the prevalence of strabismus was $1.5 \% .{ }^{17}$

\section{Conclusion}

Prevalence of strabismus was found to be high as compare to other countries. The manifest strabismus was more common than latent strabismus. Squint has immediate (Childhood) and long-term (I.e. during adulthood) effects on the life of the children. Timely diagnosis and treatment can improve prognosis and thus quality of life too.

\section{Ethical approval}

Ethical approval was taken from the institutional review board of the institution where the samples were drawn.

\section{Informed consent}

An informed consent was taken from the parents of the child before taking sample.

\section{Fund status}

There were no funding involved in this study. Patients were selected from Out-patient department.

\section{Authors' conflict of interest}

The authors declared that there was no conflict between the authors of this study.

\section{References}

1. Rice A, Nsengimana J, Simmons IG, et al. Replication of the recessive STBMSI Locus but with dominant inheritance. Invest Ophthalmol Vis Sci. 2009;50(7):3210-3217.

2. Epidemiology of strabismus. Ophthalmic Physiol Opt. 1997;17(6):536539.

3. Attada TR, Deepika M, Laxmi S. Strabismus in paediatric age (3-16 year): a clinical study. Int J Res Med Sci. 2016;4:1903-1909.

4. Chia A, Dirani M, Chan YH, et al. Prevalence of amblyopia and strabismus in young Singaporean Chinese children. Investigative ophthalmology \& visual science. 2010;1;51(7):3411-3417.

5. Green-Simms AE, Mohney BG. Epidemiology of pediatric strabismus. InPediatric ophthalmology. Neuro-ophthalmology, genetics. 2010; p. $1-9$

6. Tanaka A, Ohno-Matsui K, Shimada N, et al. Prevalence of strabismus in patients with pathologic myopia. Journal of medical and dental sciences. 2010;57(1):75-82.

7. Azonobi IR, Olatunji FO, Adido J, et al. Vision of strabismic children in Ilorin, Nigeria. Nigerian Journal of Ophthalmology. 2008;16(1):12-15.

8. Abbas M, Rahman HU, Butt IA, et al. Prevalence and mode of presentation of vertical deviations in squint patients. $R M J$. 2005;30(2):79-81. 
9. Asif M, Habiba U, Khan MW, et al. Frequency Of Major Types Of Manifest Strabismus Among Patients Of Age Group 1 To 25 Years Presented To Benazir Bhutto Hospital Rawalpindi. Pak J Med Biol Sci. 2017;1(1):30-34.

10. Amir S, Khan DA, Asrar A. et al. Prevalence of Refractive Errors Causing Amblyopia in Children. Opthamology Update. 2017;15(3):251-253.

11. Chen X, Fu Z, Yu J, et al. Prevalence of amblyopia and strabismus in Eastern China: results from screening of preschool children aged 36-72 months. British Journal of Ophthalmology. 2016;100(4):515-519.

12. Chegeni M, Khanjani N, Rahmatpour $\mathrm{P}$, et al. The prevalence of amblyopia in Iran: A systematic review. Journal of current ophthalmology. 2018;30(3):1-8.

13. Awan MA, Ahmad I, Khan AA. Prevalence of Amblyopia among Government Middle School Children in City Of Lahore, Pakistan. Int J Agro Veterinary Med Sci. 2010;4:41-46.
14. Polling JR, Loudon SE, Klaver CC. Prevalence of amblyopia and refractive errors in an unscreened population of children. Optom Vis Sci. 2012;89:e44-e49.

15. Fu J, Li SM, Li JL, et al. Screening for amblyopia among grade-1 students in primary school with ncorrected vision and stereopsis test in central China. Chin Med J (Engl). 2013;126:903-908.

16. Shafique MM, Ullah N, Butt NH, et al. Incidence of Amblyopia in Strabismic population. PakJ Ophthalmol. 2007;23: 1-6.

17. Faghihi M, Ostadimoghaddam H, Fatemi A, et al. The Prevalence of Refractive Errors, Strabismus and Amblyopia in Schoolboys of Varamin, Iran, in 2010. Iranian J Ophthalmol. 2012;24:33-39. 